Check for updates

Cite this: J. Mater. Chem. C, 2018, 6, 6996

Received 19th April 2018, Accepted 6th June 2018

DOI: $10.1039 / \mathrm{c} 8 \mathrm{tc} 01871 \mathrm{e}$

rsc.li/materials-c

\section{Efficient perovskite light-emitting diodes based on a solution-processed tin dioxide electron transport layer $\dagger$}

\author{
Heyong Wang, ${ }^{a}$ Hongling $Y u,{ }^{a}$ Weidong $\mathrm{Xu}$, DD $^{\mathrm{a}}$ Zhongcheng Yuan, ${ }^{\mathrm{a}}$ Zhibo Yan, ${ }^{\mathrm{ab}}$ \\ Chuanfei Wang, ${ }^{a}$ Xianjie Liu, ${ }^{a}$ Mats Fahlman, ${ }^{a}$ Jun-Ming Liu, ${ }^{b}$ Xiao-Ke Liu (D) *acd \\ and Feng Gao (D) *a
}

\begin{abstract}
To achieve high-performance perovskite light-emitting diodes (PeLEDs), an appropriate functional layer beneath the perovskite emissive layer is significantly important to modulate the morphology of the perovskite film and to facilitate charge injection and transport in the device. Herein, for the first time, we report efficient $n-i-p$ structured PeLEDs using solution-processed $\mathrm{SnO}_{2}$ as an electron transport layer. Three-dimensional perovskites, such as $\mathrm{CH}\left(\mathrm{NH}_{2}\right)_{2} \mathrm{Pbl}_{3}$ and $\mathrm{CH}_{3} \mathrm{NH}_{3} \mathrm{Pbl}_{3}$, are found to be more chemically compatible with $\mathrm{SnO}_{2}$ than with commonly used $\mathrm{ZnO}$. In addition, $\mathrm{SnO}_{2}$ shows good transparency, excellent morphology and suitable energy levels. These properties make $\mathrm{SnO}_{2}$ a promising candidate in both three- and low-dimensional PeLEDs, among which a high external quantum efficiency of $7.9 \%$ has been realized. Furthermore, interfacial materials that are widely used to improve the device performances of $\mathrm{ZnO}$-based PeLEDs are also applied on $\mathrm{SnO}_{2}$-based PeLEDs and their effects have been systematically studied. In contrast to $\mathrm{ZnO}, \mathrm{SnO}_{2}$ modified by these interfacial materials shows detrimental effects due to photoluminescence quenching.
\end{abstract}

\section{Introduction}

Metal halide perovskites have attracted enormous attention in recent years as promising semiconducting materials in optoelectronic applications, such as solar cells, light-emitting diodes (LEDs), lasers, transistors and photodetectors. ${ }^{1-5}$ These materials show exceptional properties such as suitable bandgaps, high absorption coefficients, low trap densities, and long carrier diffusion lengths, leading to rapid progress in solar cells, among which a high power conversion efficiency (PCE) over $22 \%$ has been achieved. ${ }^{6,7}$ Furthermore, they also exhibit outstanding light-emitting properties, such as high colour purity, readily tuneable emissions and high photoluminescence quantum yields (PLQYs), making them promising candidates for displays and lighting applications. ${ }^{8,9}$ Within the last four years, increasing

\footnotetext{
${ }^{a}$ Department of Physics, Chemistry and Biology (IFM), Linköping University, Linköping 58183, Sweden.E-mail: xiaoke.liu@liu.se,feng.gao@liu.se

${ }^{b}$ Laboratory of Solid State Microstructures, Innovation Center of Advanced Microstructures, Nanjing University, Nanjing 210093, P. R. China

${ }^{c}$ State Key Laboratory of Luminescent Materials and Devices, South China University of Technology, Guangzhou 510640, P. R. China

${ }^{d}$ State Key Lab of Silicon Materials, Zhejiang University, Hangzhou 310027, P. R. China

$\dagger$ Electronic supplementary information (ESI) available. See DOI: 10.1039/c8tc01871e
}

efforts have been devoted to developing efficient perovskite LEDs (PeLEDs). ${ }^{10-17}$

To realize high-efficiency PeLEDs, charge transport layers, including hole transport layers (HTLs) and electron transport layers (ETLS), are employed to balance hole- and electroninjection and transport. ${ }^{18}$ In general, there are two types of device architectures for PeLEDs, $\mathrm{p}-\mathrm{i}-\mathrm{n}$ and $\mathrm{n}-\mathrm{i}-\mathrm{p}$, which refer to a layer preparation sequence in the form of a p-type layer, an intrinsic layer and an n-type layer and the reverse sequence, respectively. For efficient $\mathrm{p}-\mathrm{i}-\mathrm{n}$ based PeLEDs, vacuumdeposited organic molecules, such as $2,2^{\prime}, 2^{\prime \prime}$-(1,3,5-benzenetriyl)tris(1-phenyl-1- $H$-benzimidazole) (TPBi) and 2,9-dimethyl-4,7diphenyl-1,10-phenanthroline (BCP), are employed as the ETLs. ${ }^{10,19}$ In contrast, efficient $\mathrm{n}-\mathrm{i}-\mathrm{p}$ based PeLEDs are fabricated through all solution processes, where colloidal zinc oxide (ZnO) nanoparticles are usually used as the ETLs. ${ }^{11,20-24}$ Despite high efficiencies in PeLEDs, ZnO could cause the problem of chemical instability in the perovskite films, ${ }^{25,26}$ limiting its applications in PeLEDs. Therefore, it is desired to develop new types of solution-processed ETLs for efficient n-i-p based PeLEDs.

Solution-processed inorganic metal oxides, such as titanium dioxide $\left(\mathrm{TiO}_{2}\right)$ and tin dioxide $\left(\mathrm{SnO}_{2}\right)$, are potential ETL candidates for efficient PeLEDs. These materials have large bandgaps, a suitable conduction band minimum (CBM) for electron 
injection and a deep valence band maximum (VBM) for hole blocking. ${ }^{27-29}$ In addition, their thin films show good transparency in the visible-infrared region of 400-900 nm, minimizing optical energy losses caused by the ETL. ${ }^{30,31}$ Efforts have been made to develop PeLEDs using solution-processed $\mathrm{TiO}_{2}$, which however show a relatively low external quantum efficiency (EQE) of $0.48 \% .{ }^{14}$ Moreover, preparation of the $\mathrm{TiO}_{2}$ layer requires hightemperature $\left(>450{ }^{\circ} \mathrm{C}\right)$ sintering, which is a barrier for low-cost and stretchable PeLEDs. In addition to $\mathrm{TiO}_{2}$, solution-processed $\mathrm{SnO}_{2}$ has also been widely used as the ETL in organic, dyesensitized, and perovskite solar cells. ${ }^{28-33}$ Furthermore, $\mathrm{SnO}_{2}$ has high mobilities $\left(\sim 240 \mathrm{~cm}^{2} \mathrm{~V}^{-1} \mathrm{~s}^{-1}\right.$ and $1.9 \times 10^{-3} \mathrm{~cm}^{2} \mathrm{~V}^{-1} \mathrm{~s}^{-1}$ for bulk and nanoparticle films, respectively) and a high electrical conductivity $\left(1.82 \times 10^{-8} \mathrm{~S} \mathrm{~cm}^{-1}\right.$ at room temperature $) .{ }^{34,35}$ For instance, You and co-workers reported hysteresis-free perovskite solar cells with PCEs of around $20 \%$ based on colloidal $\mathrm{SnO}_{2}$ nanoparticles. ${ }^{34}$ Given that the $\mathrm{SnO}_{2}$ film has suitable energy levels, good transparency and high electron mobility, it is thus natural to expect that the use of the solution-processed $\mathrm{SnO}_{2}$ ETL would be a fruitful approach for obtaining high-efficiency solution-processed PeLEDs.

Herein, for the first time, we report efficient $n-i-p$ structured PeLEDs using solution-processed $\mathrm{SnO}_{2}$ as the ETL. It is found that three-dimensional (3D) perovskites, such as $\mathrm{CH}\left(\mathrm{NH}_{2}\right)_{2} \mathrm{PbI}_{3}$ $\left(\mathrm{FAPbI}_{3}\right)$ and $\mathrm{CH}_{3} \mathrm{NH}_{3} \mathrm{PbI}_{3}\left(\mathrm{MAPbI}_{3}\right)$, show considerably enhanced chemical compatibility with $\mathrm{SnO}_{2}$ compared with ZnO. More importantly, both 3D- and low-dimensional perovskite based PeLEDs using $\mathrm{SnO}_{2}$ as the ETL exhibit high efficiencies, among which a high EQE of 7.9\% has been realized. These results suggest that $\mathrm{SnO}_{2}$ can be used as an efficient ETL in solution-processed PeLEDs. Furthermore, interfacial materials, such as polyethylenimine ethoxylated (PEIE) and polyethylenimine (PEI), that have been widely used to improve the device performances of $\mathrm{ZnO}$ based PeLEDs are also employed in $\mathrm{SnO}_{2}$-based PeLEDs, the effects of which have been systematically studied. Unexpectedly, these two interfacial materials show detrimental effects on $\mathrm{SnO}_{2}$ based PeLEDs due to photoluminescence quenching.

\section{Results and discussion}

The morphology of the $\mathrm{SnO}_{2}$ film obtained by spin-coating colloidal $\mathrm{SnO}_{2}$ nanoparticles on an ITO-coated glass substrate is investigated by using atomic force microscopy (AFM). As shown in Fig. 1a, a smooth and pinhole-free $\mathrm{SnO}_{2}$ film with a root-mean-square (RMS) roughness of $1.24 \mathrm{~nm}$ is obtained. Fig. 1b shows the transmission spectra of the $\mathrm{SnO}_{2}$ and $\mathrm{ZnO}$ films prepared on ITO-coated glass substrates, respectively. The $\mathrm{SnO}_{2}$ film exhibits similar transparency to the $\mathrm{ZnO}$ film between 420 and $850 \mathrm{~nm}$. Note that the $\mathrm{SnO}_{2}$ film shows excellent transparency with transmission values greater than $97 \%$ in the ultraviolet-visible-infrared region, suggesting that the $\mathrm{SnO}_{2}$ layer will cause minimized optical energy losses in PeLEDs with a wide range of emissive wavelengths. In particular, in the ultraviolet region below $400 \mathrm{~nm}$, where the $\mathrm{ZnO}$ film starts to absorb light (the bandgap of $\mathrm{ZnO}$ is $\sim 3.53 \mathrm{eV}$ ), ${ }^{36}$ the $\mathrm{SnO}_{2}$
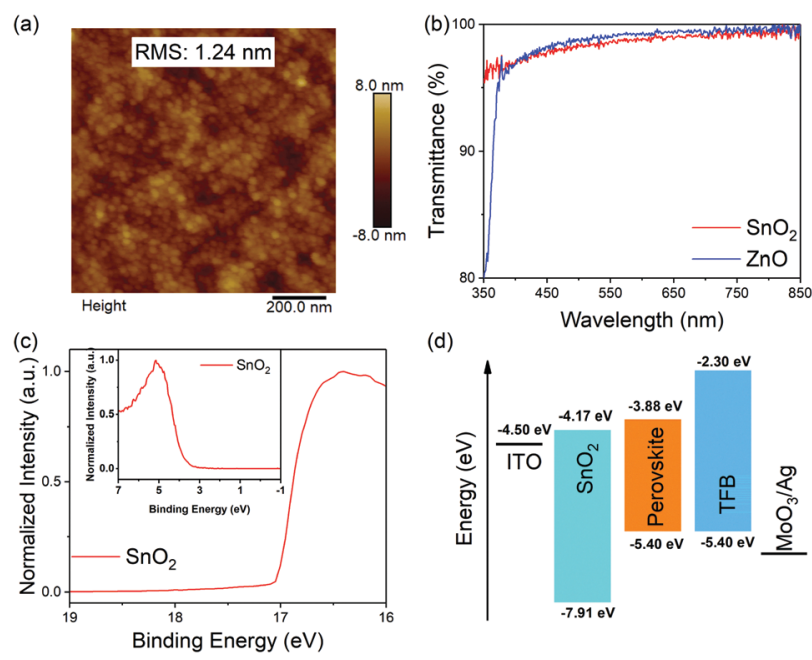

(d)

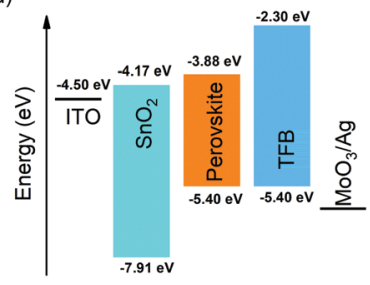

Fig. 1 (a) AFM height image of the $\mathrm{SnO}_{2}$ film. (b) Transmission spectra of the $\mathrm{SnO}_{2}$ and $\mathrm{ZnO}$ films deposited on ITO-coated glass substrates, respectively. (c) UPS cutoff edge of the $\mathrm{SnO}_{2}$ film, inset: valence band edge. (d) Flat-band energy-level diagram of the materials used in this study.

film still shows good transparency with transmission values greater than $95 \%$ due to a much larger bandgap of $\sim 3.74 \mathrm{eV},{ }^{34}$ showing promise as a good ETL candidate for ultraviolet LEDs.

The electronic states and band structures of the $\mathrm{SnO}_{2}$ film and a low-dimensional perovskite film consisting of $\mathrm{FAPbI}_{3}$ : 60 mol\% NMAI (NMAI $=\mathrm{C}_{10} \mathrm{H}_{7} \mathrm{CH}_{2} \mathrm{NH}_{2} \cdot \mathrm{HI}$ ) are studied by ultraviolet photoelectron spectroscopy (UPS). The work functions (WFs) of the $\mathrm{SnO}_{2}$ and perovskite films are calculated to be $-4.17 \mathrm{eV}$ and $-4.18 \mathrm{eV}$, respectively (Fig. 1c and Fig. S1a, ESI $\dagger$ ). The CBM and VBM of the perovskite film calculated from the UPS spectra and Tauc plot (Fig. S1b, ESI $\dagger$ ) are $-3.88 \mathrm{eV}$ and $-5.40 \mathrm{eV}$, respectively. As shown in Fig. 1d, the CBM of the $\mathrm{SnO}_{2}$ layer matches well with that of the perovskite layer, facilitating efficient electron injection from the ETL into the perovskite emissive layer; the valence band maximum of the $\mathrm{SnO}_{2}$ layer $(-7.91 \mathrm{eV})$ is much deeper than that of the perovskite layer, offering efficient hole blocking. Therefore, the $\mathrm{SnO}_{2}$ film exhibits smooth morphology, excellent transparency and suitable energy levels, which is promising as an ETL candidate for PeLEDs.

We use a one-step spin-coating method to form 3D perovskite films $\left(\mathrm{FAPbI}_{3}\right.$ and $\left.\mathrm{MAPbI}_{3}\right)$ on the $\mathrm{SnO}_{2}$ and $\mathrm{ZnO}$ films with various annealing temperatures to study their chemical compatibility with the underlying $\mathrm{SnO}_{2}$ and $\mathrm{ZnO}$, respectively. The crystal structures of these films are investigated by X-ray diffraction (XRD). As shown in Fig. 2a, the $\mathrm{FAPbI}_{3}$ films deposited on $\mathrm{SnO}_{2}$ show a dominant diffraction peak at $11.8^{\circ}$ when they are annealed below $120{ }^{\circ} \mathrm{C}$, which can be assigned to the (010) lattice plane of the yellow phase. ${ }^{37,38}$ Interestingly, a diffraction peak at $13.9^{\circ}$ that belongs to the (111) lattice plane of the black phase can be observed when annealed at $120{ }^{\circ} \mathrm{C}$, accompanied by the colour change of the perovskite films (Fig. 2a). When they are annealed above $120{ }^{\circ} \mathrm{C}$, the $\mathrm{FAPbI}_{3}$ films start to decompose into lead iodide $\left(\mathrm{PbI}_{2}\right)$, the (001) lattice plane of which is 

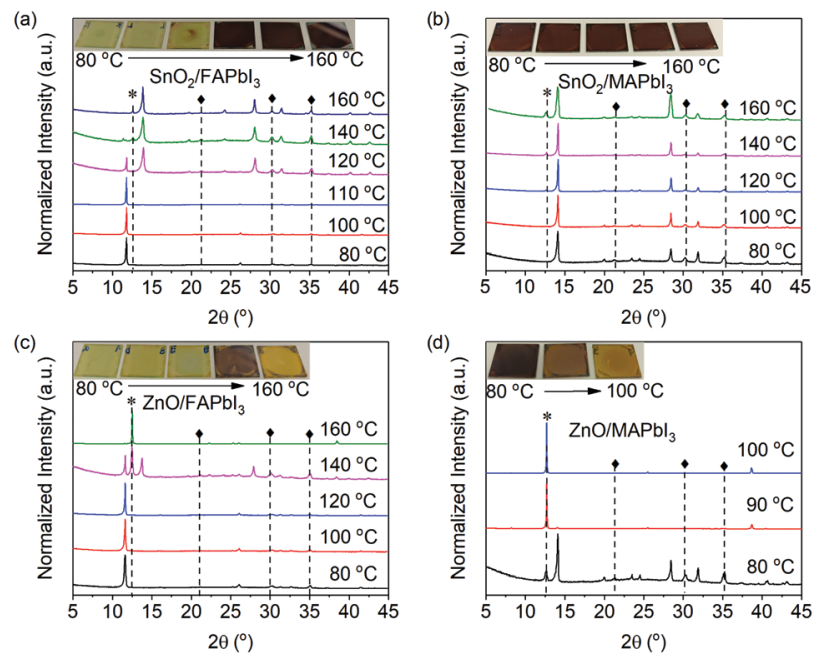

Fig. 2 XRD patterns and photographs of 3D perovskite films deposited on the $\mathrm{SnO}_{2}$ and $\mathrm{ZnO}$ films with various annealing temperatures. (a) $\mathrm{FAPbl}_{3}$ films deposited on $\mathrm{SnO}_{2}$, (b) $\mathrm{MAPb}_{3}$ films deposited on $\mathrm{SnO}_{2}$. (c) $\mathrm{FAPbl}_{3}$ films deposited on $\mathrm{ZnO}$. (d) $\mathrm{MAPbl}_{3}$ films deposited on $\mathrm{ZnO}$. * represents the diffraction peak of $\mathrm{Pbl}_{2}$ represents the diffraction peak of ITO.

located at $12.6^{\circ}$. However, it is worth noting that the $\mathrm{FAPbI}_{3}$ film shows a pure black phase when annealed at $160{ }^{\circ} \mathrm{C}$ for $1 \mathrm{~min}$ although decomposition starts at longer annealing times (Fig. S2, ESI $\dagger$ ). In comparison, the $\mathrm{FAPbI}_{3}$ films deposited on $\mathrm{ZnO}$ start to decompose into $\mathrm{PbI}_{2}$ when the annealing temperature is higher than $120{ }^{\circ} \mathrm{C}$, below which the films are in the yellow phase. The colour of the films is an obvious indication showing the change of the phases (Fig. 2c). Similarly, the $\mathrm{MAPbI}_{3}$ films deposited on $\mathrm{ZnO}$ starts to decompose into $\mathrm{PbI}_{2}$ when annealed at $80{ }^{\circ} \mathrm{C}$, and the diffraction peak of $\mathrm{MAPbI}_{3}$ is hardly observed when annealed at $90{ }^{\circ} \mathrm{C}$ and $100{ }^{\circ} \mathrm{C}$, accompanied by an obvious colour change of the films (Fig. 2d). It is impressive that the $\mathrm{MAPbI}_{3}$ films deposited on $\mathrm{SnO}_{2}$ are stable below $100{ }^{\circ} \mathrm{C}$; no obvious colour change of the perovskite films is observed at a high annealing temperature up to $160{ }^{\circ} \mathrm{C}$ (Fig. 2b). These results demonstrate that the 3D perovskite films show considerably enhanced chemical compatibility with $\mathrm{SnO}_{2}$ compared with $\mathrm{ZnO}$, suggesting feasible applications of $\mathrm{SnO}_{2}$ in PeLEDs where perovskite films require a wide range of annealing temperatures.

We further study the morphologies and optoelectronic properties of the $\mathrm{FAPbI}_{3}$ film (annealed at $120{ }^{\circ} \mathrm{C}$ ) deposited on $\mathrm{SnO}_{2}$. As shown in Fig. 3a and b, the film shows smooth (RMS: $9.3 \mathrm{~nm}$ ) and pinhole-free morphologies with large grains. The absorption and PL spectra of the $\mathrm{FAPbI}_{3}$ film deposited on $\mathrm{SnO}_{2}$ were also measured and are shown in Fig. S3 (ESI $\dagger$ ). The absorption onset is located at $813 \mathrm{~nm}$, corresponding to an energy bandgap of $1.52 \mathrm{eV}$. In addition, this film shows narrow emission peaked at $811 \mathrm{~nm}$ with a PLQY of 7\%. A PeLED is fabricated with the structure of indium tin oxide (ITO) $/ \mathrm{SnO}_{2}$ $(30 \mathrm{~nm}) / \mathrm{FAPbI}_{3}$ (480 nm)/poly(9,9-dioctyl-fluorene-co- $N$-(4-butylphenyl)diphenylamine) (TFB, $40 \mathrm{~nm}) / \mathrm{MoO}_{3}(7 \mathrm{~nm}) / \mathrm{Ag}(80 \mathrm{~nm})$. As shown in Fig. 3c, the device has a very low turn-on voltage (the driving voltage when emission is detectable) of $1.2 \mathrm{~V}$ and a
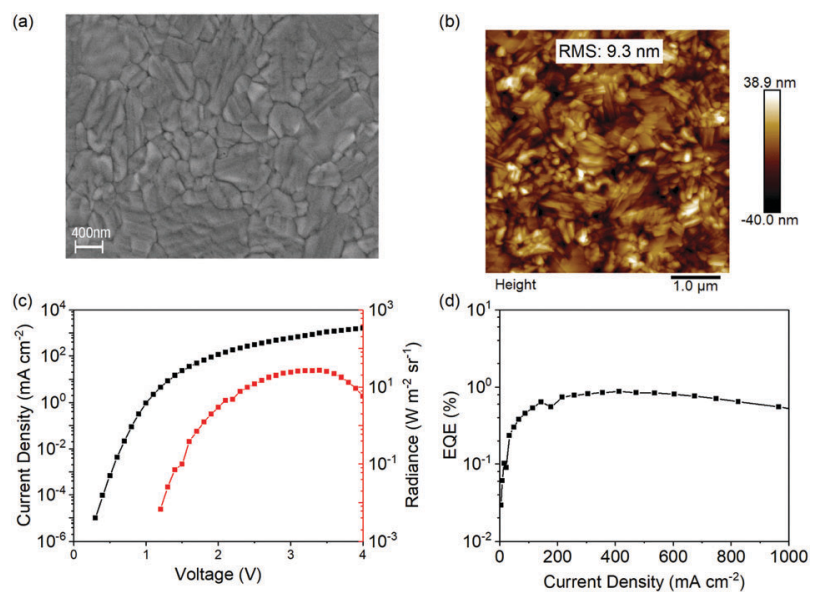

Fig. 3 (a) SEM image and (b) AFM image of the FAPbl 3 film deposited on $\mathrm{SnO}_{2}$. (c) Current density-voltage-radiance and (d) EQE-current density curves of the device based on $\mathrm{FAPbl}_{3}$ deposited on $\mathrm{SnO}_{2}$.

maximum radiance of $26 \mathrm{~W} \mathrm{sr}^{-1} \mathrm{~m}^{-2}$. It is interesting to note that the turn-on voltage $\left(V_{\text {on }}\right)$ of this device is quite lower than the theoretical limit of $1.52 \mathrm{~V}$ according to the bandgap $\left(E_{\mathrm{g}}\right)$ of $\mathrm{FAPbI}_{3}\left(V_{\mathrm{on}}^{\text {theoretical }}=E_{\mathrm{g}} / e\right.$, where $e$ is the unit charge $)$, which may be explained by an Auger-assisted energy upconversion model. ${ }^{39-41}$ Since TFB has a hole mobility of $\sim 1.0 \times$ $10^{-2} \mathrm{~cm}^{2} \mathrm{~V}^{-1} \mathrm{~s}^{-1}$ which is an order of magnitude higher than that of the electron mobility of the $\mathrm{SnO}_{2}$ nanoparticle film, there is a negligible hole injection barrier between the perovskite layer and TFB. ${ }^{42}$ Thus, holes and electrons are likely to accumulate at the interface between $\mathrm{SnO}_{2}$ and the perovskite layer. With electrons accumulating at the interface, an Augerassisted electron injection process can take place, in which one high-energy electron can be generated after absorbing the energy released from the interfacial recombination of an electron-hole pair. The resulting high-energy electron can overcome the injection barrier between the perovskite layer and $\mathrm{SnO}_{2}$ and recombine with the hole inside the perovskite EML to emit a photon. In addition, this device exhibits a very low EQE at low current density which increases to a moderate maximum value of $0.9 \%$ at a high current density of $\sim 400 \mathrm{~mA} \mathrm{~cm}^{-2}$. This finding can be explained by the low exciton binding energy of the large-grain $\mathrm{FAPbI}_{3}$ crystals, where non-radiative trapassisted recombination is dominant at low carrier excitation densities and radiative bimolecular recombination gradually increases with increasing excitation density. ${ }^{43}$

In order to investigate the generality of the $\mathrm{SnO}_{2}$ ETL in PeLEDs, we further investigated low-dimensional perovskites prepared on $\mathrm{SnO}_{2}$. Low-dimensional perovskites can be synthesized by incorporating bulky organic ammonium cations that are too large to fit into the interspace between the $\mathrm{PbX}_{6}{ }^{4-}(\mathrm{X}=\mathrm{I}$, $\mathrm{Br}$, and $\mathrm{Cl}$ ) octahedral layers and therefore split large perovskite grains into different types of nanocrystals..$^{20,43,44}$ In this study, we prepare a series of low-dimensional perovskites by adjusting the molar ratios between 1-naphthylmethylammonium iodide (NMAI) and $\mathrm{FAPbI}_{3}$, expressed as $\mathrm{FAPbI}_{3}: x$ mol $\%$ NMAI $(x=20,40$, 60,80 , and 100). These films are formed by one-step spin-coating 


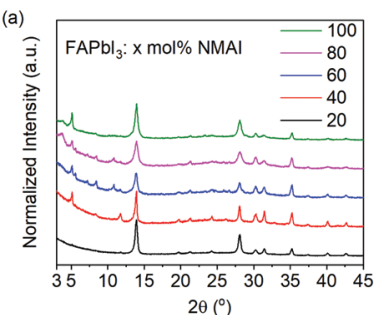

(b)
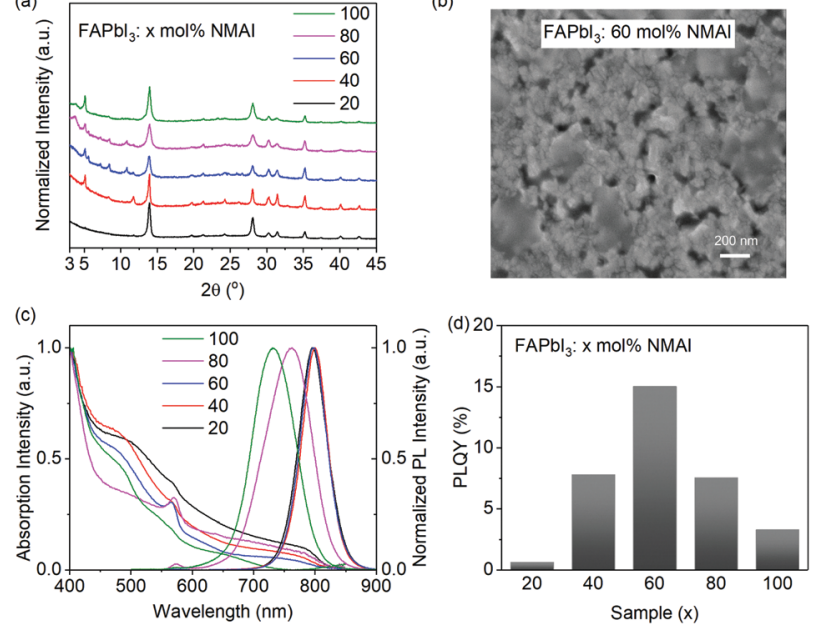

Fig. 4 (a) XRD patterns, (b) top-view SEM image, (c) absorption and PL spectra, and (d) PLQYs of FAPbl 3 : $x$ mol\% NMAI $(x=20,40,60,80$, and 100) films prepared on $\mathrm{SnO}_{2}$

from precursor solutions on $\mathrm{SnO}_{2}$, followed by thermal annealing at $100{ }^{\circ} \mathrm{C}$. XRD measurements are conducted to determine the composition and crystallinity of the perovskite films. As mentioned above, the $\mathrm{FAPbI}_{3}$ film annealed at $100{ }^{\circ} \mathrm{C}$ is in the yellow phase (Fig. 2a), whereas the addition of NMAI lowers the transition temperature of the black phase (Fig. 4a). With 20 mol\% NMAI, most of the perovskites have been transferred into the black phase. With further increasing ratios of NMAI, the diffraction peaks assigned to layered perovskites are observed, indicating that the as-formed films are composed of grains distinct from the 3D perovskites. The average crystal sizes of the low-dimensional perovskite films are calculated from the XRD results by using the Debye-Scherrer equation (eqn (S1), ESI $\dagger$ ). As shown in Table S1 (ESI $\dagger$ ), the addition of NMAI gradually decreases the average crystal size from $28.3 \mathrm{~nm}\left(3 \mathrm{D} \mathrm{FAPbI}_{3}\right)$ to $16.2 \mathrm{~nm}(x=0.8)$. The top-view scanning electron microscopy (SEM) image of $\mathrm{FAPbI}_{3}$ : 60 mol\% NMAI clearly shows the formation of tiny grains (Fig. 4b). AFM measurements are also performed to investigate the morphology of this film. As shown in Fig. S4 (ESI $\dagger$ ), the film consists of small grains and exhibits a RMS of $16.6 \mathrm{~nm}$.

The normalized absorption and PL spectra of these lowdimensional perovskite films are shown in Fig. 4c. The addition of 20 and $40 \mathrm{~mol} \% \mathrm{NMAI}$ to $\mathrm{FAPbI}_{3}$ slightly changes the absorption and PL spectra, whereas more amounts of NMAI induce the formation of the $\langle n=2\rangle$-layered perovskite, in which the characteristic absorption peak is located at $573 \mathrm{~nm} .^{20,44,45}$ The PL spectra, peaked at $798 \mathrm{~nm}$ with a full width at half maximum (FWHM) of $54 \mathrm{~nm}$, almost remain the same when the NMAI contents are below $60 \mathrm{~mol} \%$. It is also interesting to note that obvious blue-shifted PL spectra are observed when 80 and 100 mol\% NMAI are introduced (PL spectra peaked at $762 \mathrm{~nm}$ and $732 \mathrm{~nm}$, respectively), which may be caused by the size-dependent quantum confinement effect. ${ }^{46}$ In addition, the FWHM of these two spectra are broadened to $89 \mathrm{~nm}(x=80)$ and $81 \mathrm{~nm}(x=100)$, respectively. The wider PL spectra may be originated from several low-dimensional
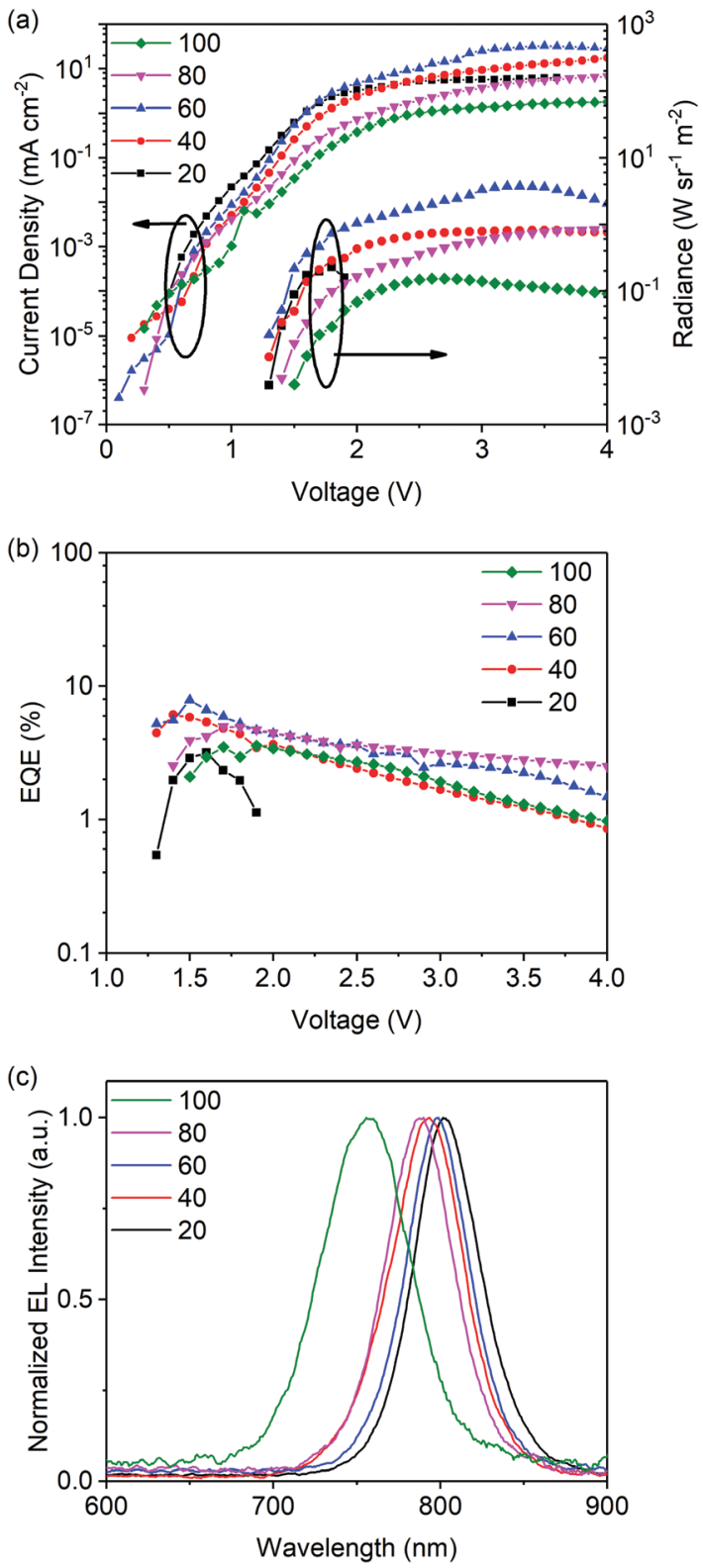

Fig. 5 (a) Current density-voltage-radiance curves, (b) EQE-voltage curves, and (c) EL spectra of low-dimensional PeLEDs with $\mathrm{FAPbl}_{3}$ : $x$ mol\% NMAI $\left(x=20,40,60,80\right.$, and 100) films as the EMLs and $\mathrm{SnO}_{2}$ as the ETLs.

emissive components - as indirect evidence of a clear PL peak at $573 \mathrm{~nm}$ that derives from the $\langle n=2\rangle$-layered perovskite can be observed. The PLQYs of these films change along with the ratios of NMAI, among which the addition of $60 \mathrm{~mol} \% \mathrm{NMAI}$ contributes to the highest PLQY of $15 \%$ (Fig. $4 \mathrm{~d}$ ).

PeLEDs are fabricated to investigate the electroluminescent (EL) properties of these low-dimensional perovskites with $\mathrm{SnO}_{2}$ as the ETL. The device structure is the same as that of the $\mathrm{FAPbI}_{3}$-based PeLED except the emitting layer. The current density-voltage-radiance curves of these PeLEDs are shown in Fig. 5a. It should be noted that the addition of NMAI gradually decreases the current densities of the devices due to the 

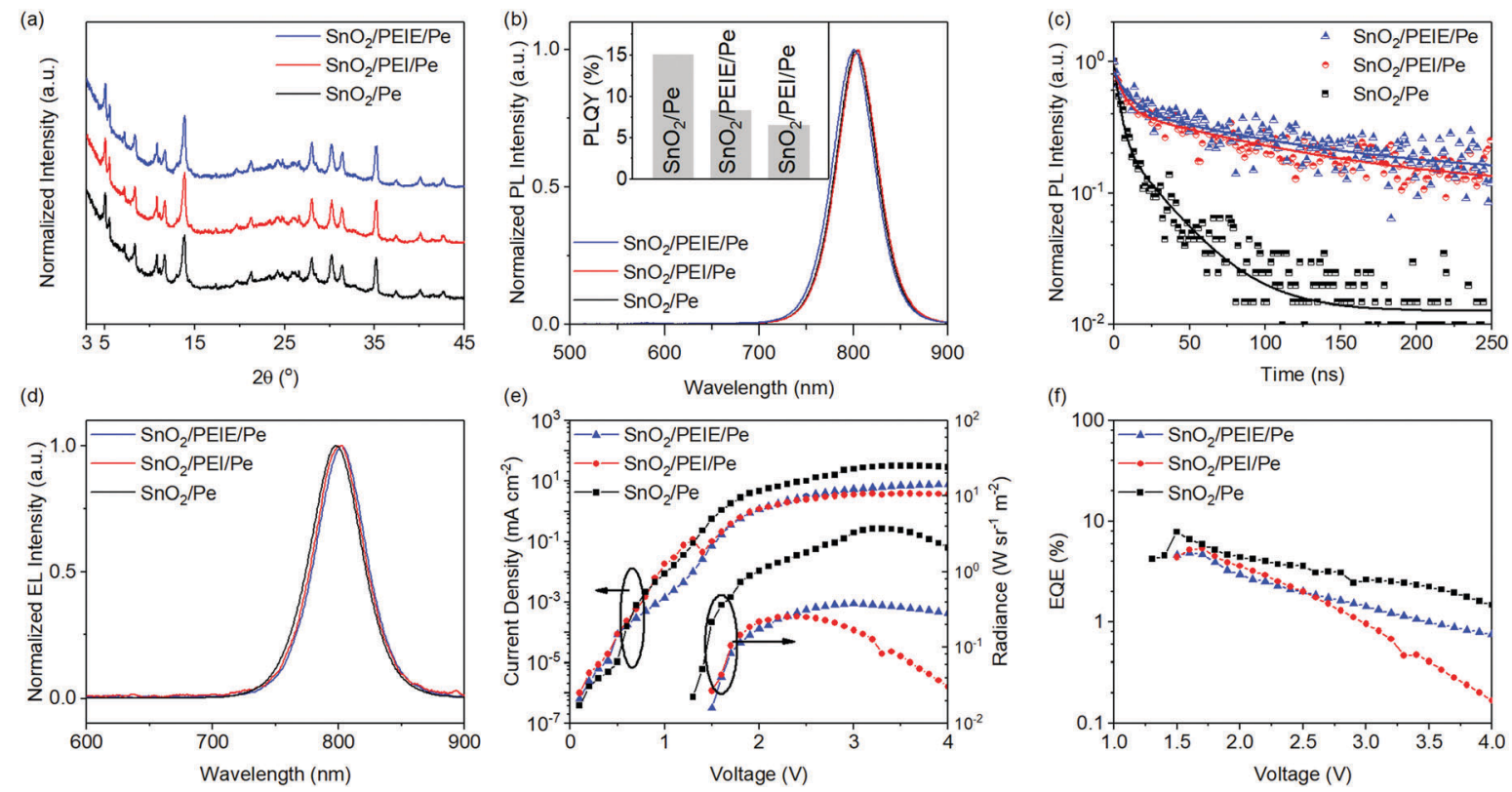

Fig. 6 (a) XRD patterns, (b) PL spectra, (c) PL decay curves of the $\mathrm{FAPbl}_{3}$ : 60 mol\% NMAl films prepared on $\mathrm{SnO}_{2}, \mathrm{SnO}_{2} / \mathrm{PEI}, \mathrm{and} \mathrm{SnO}_{2} / \mathrm{PEIE}$, respectively. (d) Normalized EL spectra, (e) current density-voltage-radiance curves and (f) EQE-voltage curves of the FAPbl 3 : 60 mol\% NMAI based PeLED devices with $\mathrm{SnO}_{2}, \mathrm{SnO}_{2} / \mathrm{PEI}$, and $\mathrm{SnO}_{2} / \mathrm{PEIE}$ as the ETLS.

insulating nature of NMAI. In addition, the $\mathrm{FAPbI}_{3}: 80 \mathrm{~mol} \%$ NMAI and $\mathrm{FAPbI}_{3}: 100$ mol\% NMAI-based devices show gradually increased turn-on voltages compared with those with lower amounts of NMAI. This can be explained by their relatively wider bandgaps. The EQE-voltage curves of these devices are shown in Fig. 5b, among which the $\mathrm{FAPbI}_{3}: 60$ mol\% NMAI based device shows the highest $\mathrm{EQE}$ of $7.9 \%$. The statistical external quantum efficiency from 44 devices presents an average $\mathrm{EQE}$ of $6.8 \%$ (Fig. S5, ESI $\dagger$ ). The results demonstrate that $\mathrm{SnO}_{2}$ is a good ETL for PeLEDs based on low-dimensional perovskites in addition to 3D perovskites. Fig. 5c shows the normalized EL spectra of these devices which exhibit a similar shift tendency to the PL spectra.

It is reported that interfacial materials, such as PEIE and PEI, can modify the ETL surface and show favourable effects on the device performances. ${ }^{11,20}$ For instance, Wang et al. reported that 3D perovskites show a better morphology of PEI-modified $\mathrm{ZnO}$, and consequently deliver higher device performances. ${ }^{11}$ In addition, these interfacial materials are able to tailor the work function of the contacts and can be used to control electron injection. ${ }^{47}$ Therefore, it is desired to study their effects on $\mathrm{SnO}_{2}$ based PeLEDs. Fig. 6a shows the XRD patterns of the $\mathrm{FAPbI}_{3}: 60 \mathrm{~mol} \% \mathrm{NMAI}$ films prepared on $\mathrm{SnO}_{2}, \mathrm{SnO}_{2} / \mathrm{PEI}$ and $\mathrm{SnO}_{2} / \mathrm{PEIE}$ substrates, respectively. These films show similar XRD patterns, suggesting that these two interfacial materials have a negligible impact on the perovskite crystal structure. The CBM of the PEIE-modified $\mathrm{SnO}_{2}$ film is changed from $-4.17 \mathrm{eV}$ to $-3.73 \mathrm{eV}$ due to the shift of the WF (Fig. S6, ESI†). The more matching energy level with the perovskite layer $(-3.88 \mathrm{eV})$ facilitates easier electron extraction from the perovskite layer. ${ }^{48}$ Although these perovskite films show similar PL spectra (Fig. 6b), the perovskite films prepared on $\mathrm{SnO}_{2} / \mathrm{PEI}$ and $\mathrm{SnO}_{2} / \mathrm{PEIE}$ exhibit gradually reduced PLQYs, indicating PL quenching caused by these interfacial materials. The transient PL decay characteristics of these perovskite films were investigated and are shown in Fig. 6c. The transient PL decay spectra are fitted with a bi-exponential decay function consisting of two time constants, suggesting a fast decay pathway and a slow decay pathway in these films. The fast decay pathway is associated with the quenching of free carriers in the perovskite domains caused by the substrate layers. As shown in Table S2 (ESI $\dagger$ ), the fraction of the short decay time constants declines in the film with PEIE (or PEI). In consideration of the thick perovskite film $(\sim 480 \mathrm{~nm}$, shown in Fig. S7, ESI $\dagger)$, the slow decay pathway can be assigned to the PL decay of the residual free carriers that are far from the interfacial layer.

The interfacial materials are then employed in PeLED devices, the performance efficiencies of which are shown in Fig. 6d-f. Compared with the device without an interfacial layer, the device using PEIE (or PEI) shows reduced current densities and higher turn-on voltages, which may be due to the insulating nature of these materials. Unlike those based on $\mathrm{ZnO}$, the device with PEIE (or PEI) modified $\mathrm{SnO}_{2}$ exhibits detrimental effects on the device performances. ${ }^{11,15}$ The PeLEDs with PEIE and PEI deliver EQEs of $4.9 \%$ and $5.4 \%$, respectively, lower than that $(7.9 \%)$ of the device without the interfacial layer. The results are in line with the PL measurements and confirm that the interfacial materials (PEIE and PEI) show detrimental effects due to increased non-radiative recombination. This observation may be useful for perovskite solar cells where charge extraction is found to be favourable.

\section{Conclusions}

In conclusion, for the first time, we have systematically studied the effects of solution-processed $\mathrm{SnO}_{2}$ as the ETL in n-i-p 
structured PeLEDs based on both three- and low-dimensional perovskites. $\mathrm{SnO}_{2}$ exhibits a smooth morphology, suitable energy levels, good electron-transporting properties and excellent transparency with transmission values greater than 95\% in ultraviolet-visible-infrared regions. In addition, the 3D perovskites $\left(\mathrm{FAPbI}_{3}\right.$ and $\mathrm{MAPbI}_{3}$ ) show considerably enhanced chemical compatibility with $\mathrm{SnO}_{2}$ compared with ZnO. A series of PeLEDs are fabricated using $\mathrm{SnO}_{2}$ as the ETL, among which a high EQE of $7.9 \%$ is realized, demonstrating that $\mathrm{SnO}_{2}$ can be a good solution-processed ETL for $n-i-p$ structured PeLEDs. Furthermore, interfacial studies suggest that the interfacial materials (PEI and PEIE) facilitate charge extraction in the $\mathrm{SnO}_{2}$ based perovskite films and consequently cause PL quenching and lower efficiencies.

\section{Conflicts of interest}

There are no conflicts to declare.

\section{Acknowledgements}

This work is supported by the ERC Starting Grant (717026), the Carl Tryggers Stiftelse, the China Scholarship Council, the European Commission Marie Skłodowska-Curie Actions (691210), CeNano and the Swedish Government Strategic Research Area in Materials Science on Functional Materials at Linköping University (Faculty Grant SFO-Mat-LiU no. 200900971). Z. Y. thanks the VINNMER and Marie SkłodowskaCurie Fellowship provided by Vinnova. X. K. Liu is a VINNMER and Marie Skłodowska-Curie Fellow (No. 2016-02051), and would like to thank financial support from the State Key Laboratory of Luminescent Materials and Devices at South China University of Technology (No. 2017-skllmd-05) and the State Key Lab of Silicon Materials at Zhejiang University (No. SKL2017-03).

\section{References}

1 Z.-K. Tan, R. S. Moghaddam, M. L. Lai, P. Docampo, R. Higler, F. Deschler, M. Price, A. Sadhanala, L. M. Pazos, D. Credgington, F. Hanusch, T. Bein, H. J. Snaith and R. H. Friend, Nat. Nanotechnol., 2014, 9, 687.

2 A. Swarnkar, A. R. Marshall, E. M. Sanehira, B. D. Chernomordik, D. T. Moore, J. A. Christians, T. Chakrabarti and J. M. Luther, Science, 2016, 354, 92.

3 G. Xing, N. Mathews, S. S. Lim, N. Yantara, X. Liu, D. Sabba, M. Grätzel, S. Mhaisalkar and T. C. Sum, Nat. Mater., 2014, 13, 476.

4 C. R. Kagan, Science, 1999, 286, 945.

5 L. Dou, Y. M. Yang, J. You, Z. Hong, W. H. Chang, G. Li and Y. Yang, Nat. Commun., 2014, 5, 5404.

6 NREL, Efficiency Chart, https:/www.nrel.gov/pv/assets/ images/efficiency-chart.png, vol. 10, 2017, accessed.

7 W. S. Yang, B. Park, E. H. Jung and N. J. Jeon, Science, 2017, 356, 1376.
8 Y. H. Kim, H. Cho, J. H. Heo, T. S. Kim, N. S. Myoung, C. L. Lee, S. H. Im and T. W. Lee, Adv. Mater., 2015, 27, 1248. 9 Y. Bekenstein, B. A. Koscher, S. W. Eaton, P. Yang and A. P. Alivisatos, J. Am. Chem. Soc., 2015, 137, 16008.

10 H. Cho, S. H. Jeong, M. H. Park, Y. H. Kim, C. Wolf, C. L. Lee, J. H. Heo, A. Sadhanala, N. S. Myoung, S. Yoo, S. H. Im, R. H. Friend and T. W. Lee, Science, 2015, 350, 1222.

11 J. Wang, N. Wang, Y. Jin, J. Si, Z. K. Tan, H. Du, L. Cheng, X. Dai, S. Bai, H. He, Z. Ye, M. L. Lai, R. H. Friend and W. Huang, Adv. Mater., 2015, 27, 2311.

12 L. Protesescu, S. Yakunin, M. I. Bodnarchuk, F. Krieg, R. Caputo, C. H. Hendon, R. X. Yang, A. Walsh and M. V. Kovalenko, Nano Lett., 2015, 15, 3692.

13 X. Zhang, H. Lin, H. Huang, C. Reckmeier, Y. Zhang, W. C. H. Choy and A. L. Rogach, Nano Lett., 2016, 16, 1415.

14 O. A. Jaramillo-Quintero, R. S. Sanchez, M. Rincon and I. Mora-Sero, J. Phys. Chem. Lett., 2015, 6, 1883.

15 G. Li, F. W. R. Rivarola, N. J. L. K. Davis, S. Bai, T. C. Jellicoe, F. De La Peña, S. Hou, C. Ducati, F. Gao, R. H. Friend, N. C. Greenham and Z. K. Tan, Adv. Mater., 2016, 28, 3528. 16 X. Yang, X. Zhang, J. Deng, Z. Chu, Q. Jiang, J. Meng, P. Wang, L. Zhang, Z. Yin and J. You, Nat. Commun., 2018, 9, 570 .

17 J. Si, Y. Liu, Z. He, H. Du, K. Du, D. Chen, J. Li, M. Xu, H. Tian, H. He, D. Di, C. Lin, Y. Cheng, J. Wang and Y. Jin, ACS Nano, 2017, 11, 11100.

18 S. A. Veldhuis, P. P. Boix, N. Yantara, M. Li, T. C. Sum, N. Mathews and S. G. Mhaisalkar, Adv. Mater., 2016, 28, 6804 .

19 Y. Ling, Z. Yuan, Y. Tian, X. Wang, J. C. Wang, Y. Xin, K. Hanson, B. Ma and H. Gao, Adv. Mater., 2016, 28, 305.

20 N. Wang, L. Cheng, R. Ge, S. Zhang, Y. Miao, W. Zou, C. Yi, Y. Sun, Y. Cao, R. Yang, Y. Wei, Q. Guo, Y. Ke, M. Yu, Y. Jin, Y. Liu, Q. Ding, D. Di, L. Yang, G. Xing, H. Tian, C. Jin, F. Gao, R. H. Friend, J. Wang and W. Huang, Nat. Photonics, 2016, 10, 699.

21 J. Duan, Q. Xiong, H. Wang, J. Zhang and J. Hu, J. Mater. Sci.: Mater. Electron., 2017, 28, 60.

22 Z.-F. Shi, X.-G. Sun, D. Wu, T.-T. Xu, S.-W. Zhuang, Y.-T. Tian, X.-J. Li and G.-T. Du, Nanoscale, 2016, 8, 10035.

23 X. Liang, S. Bai, X. Wang, X. Dai, F. Gao, B. Sun, Z. Ning, Z. Ye and Y. Jin, Chem. Soc. Rev., 2017, 46, 1730.

24 Y.-Z. Zheng, E.-F. Zhao, F.-L. Meng, X.-S. Lai, X.-M. Dong, J.-J. Wu and X. Tao, J. Mater. Chem. A, 2017, 5, 12416.

25 G. Yang, H. Tao, P. Qin, W. Ke and G. Fang, J. Mater. Chem. A, 2016, 4, 3970.

26 J. Yang, B. D. Siempelkamp, E. Mosconi, F. De Angelis and T. L. Kelly, Chem. Mater., 2015, 27, 4229.

27 B. Bob, T. Bin Song, C. C. Chen, Z. Xu and Y. Yang, Chem. Mater., 2013, 25, 4725.

28 W. Q. Wu, F. Huang, D. Chen, Y. B. Cheng and R. A. Caruso, Adv. Funct. Mater., 2015, 25, 3264.

29 H. J. Snaith and C. Ducati, Nano Lett., 2010, 10, 1259.

30 F. Gu, S. F. Wang, M. K. Lü, G. J. Zhou, D. Xu and D. R. Yuan, J. Phys. Chem. B, 2004, 108, 8119. 
31 P. Tao, Y. Li, A. Rungta, A. Viswanath, J. Gao, B. C. Benicewicz, R. W. Siegel and L. S. Schadler, J. Mater. Chem., 2011, 21, 18623.

32 Q. Dong, Y. Shi, K. Wang, Y. Li, S. Wang, H. Zhang, Y. Xing, Y. Du, X. Bai and T. Ma, J. Phys. Chem. C, 2015, 119, 10212.

33 J. Song, E. Zheng, J. Bian, X.-F. Wang, W. Tian, Y. Sanehira and T. Miyasaka, J. Mater. Chem. A, 2015, 3, 10837.

34 Q. Jiang, L. Zhang, H. Wang, X. Yang, J. Meng, H. Liu, Z. Yin, J. Wu, X. Zhang and J. You, Nat. Energy, 2016, 2, 16177.

35 F. Yakuphanoglu, J. Alloys Compd., 2009, 470, 55.

36 K. Qasim, B. Wang, Y. Zhang, P. Li, Y. Wang, S. Li, S. T. Lee, L. S. Liao, W. Lei and Q. Bao, Adv. Funct. Mater., 2017, 27, 1606874 .

37 C. C. Stoumpos, C. D. Malliakas and M. G. Kanatzidis, Inorg. Chem., 2013, 52, 9019.

38 Q. Han, S. H. Bae, P. Sun, Y. T. Hsieh, Y. Yang, Y. S. Rim, H. Zhao, Q. Chen, W. Shi, G. Li and Y. Yeng, Adv. Mater., 2016, 28, 2253.

39 L. Qian, Y. Zheng, J. Xue and P. H. Holloway, Nat. Photonics, 2011, 5, 543.

40 A. K. Pandey and J. M. Nunzi, Adv. Mater., 2007, 19, 3613.

41 H. Shen, W. Cao, N. T. Shewmon, C. Yang, L. S. Li and J. Xue, Nano Lett., 2015, 15, 1211.
42 H. H. Fong, A. Papadimitratos and G. G. Malliaras, Appl. Phys. Lett., 2006, 89, 172116.

43 M. Yuan, L. N. Quan, R. Comin, G. Walters, R. Sabatini, O. Voznyy, S. Hoogland, Y. Zhao, E. M. Beauregard, P. Kanjanaboos, Z. Lu, D. H. Kim and E. H. Sargent, Nat. Nanotechnol., 2016, 11, 872.

44 Z. Xiao, R. A. Kerner, L. Zhao, N. L. Tran, K. M. Lee, T. W. Koh, G. D. Scholes and B. P. Rand, Nat. Photonics, 2017, 11, 108.

45 Z. Chen, C. Zhang, X. F. Jiang, M. Liu, R. Xia, T. Shi, D. Chen, Q. Xue, Y. J. Zhao, S. Su, H. L. Yip and Y. Cao, Adv. Mater., 2017, 8, 29.

46 J. A. Sichert, Y. Tong, N. Mutz, M. Vollmer, S. Fischer, K. Z. Milowska, R. García Cortadella, B. Nickel, C. Cardenas-Daw, J. K. Stolarczyk, A. S. Urban and J. Feldmann, Nano Lett., 2015, 15, 6521.

47 Y. Zhou, C. Fuentes-Hernandez, J. Shim, J. Meyer, A. J. Giordano, H. Li, P. Winget, T. Papadopoulos, H. Cheun, J. Kim, M. Fenoll, A. Dindar, W. Haske, E. Najafabadi, T. M. Khan, H. Sojoudi, S. Barlow, S. Graham, J. L. Brédas, S. R. Marder, A. Kahn and B. Kippelen, Science, 2012, 336, 327. 48 H. Zhou, Q. Chen, G. Li, S. Luo, T.-b. Song, H.-S. Duan, Z. Hong, J. You, Y. Liu and Y. Yang, Science, 2014, 345, 542. 